\title{
Science Students' Information Literacy Needs: A Survey of Science Faculty on What and When Each Skill Is Needed
}

\section{Richelle Witherspoon, Philip Taber, and Alex Goudreau}

\begin{abstract}
In this study, undergraduate science instructors and faculty were surveyed and interviewed to investigate the information literacy needs specific to their disciplines. Respondents shared their perspectives on IL skill development throughout science degrees and the dependence of that skill development on successful study within the field. Analysis of the results expands on current understanding of the types of resources most useful to early degree students, the most appropriate IL skills to prioritize as students progress through their degrees, and the challenges that reading and critiquing primary research pose for students. Findings from the study align with previous research on information use and literacy in the sciences and build on it by offering librarians greater insight into what underlies, drives, and impedes IL skill development for science students. Practice recommendations based on study findings are made for librarians teaching science students.
\end{abstract}

\section{Introduction}

Librarians have been grappling with the importance of information literacy (IL) in postsecondary education for decades. ${ }^{1}$ Recent work shows that IL instruction correlates strongly with measures of student success, ${ }^{2}$ and a great deal of research in the library literature has been dedicated to developing an understanding of student IL needs. ${ }^{3}$ There is also a recognition of the differences between disciplines and how those differences might impact IL needs and development. However, the specific needs of individual fields are not well known, something that is especially true in the natural sciences. To address this, the present study used surveys and interviews from undergraduate science instructors and faculty to better inform librarians on the needs of undergraduate science students as they complete their degrees. The study focused on faculty and instructor perceptions of the most appropriate resources and skills needed at each point in their students' degrees, and the challenges facing science students when interacting with the literature in their disciplines. In addition to providing specific instructional targets for

\footnotetext{
* Richelle Witherspoon is Information Services Librarian in the Harriet Irving Library at the University of New Brunswick; email: rwithers@unb.ca. Philip Taber is Business, Humanities E Languages Librarian in the Hans W. Klohn Commons at the University of New Brunswick; email: philip.taber@unb.ca. Alex Goudreau is Science and Health Sciences Librarian in the Hans W. Klohn Commons at the University of New Brunswick; email: alex. goudreau@unb.ca. (2022, Richelle Witherspoon, Philip Taber, and Alex Goudreau, Attribution-NonCommercial (https://creativecommons.org/licenses/by-nc/4.0/) CC BY-NC.
} 
information literacy, this project reveals some common misconceptions in science IL instruction and some of the factors influencing student interactions with information. It may also have implications on broader library practices by helping science librarians select resources more appropriate and intellectually accessible to their student populations.

\section{The Importance of IL Instruction}

The positive correlation of IL skills for undergraduate students is well established in the literature. Bowles-Terry, ${ }^{4}$ Vance, Kirk, and Gardner, ${ }^{5}$ and Blake et al. ${ }^{6}$ all report a positive correlation between IL instruction and GPA. Other studies draw similar conclusions. ${ }^{7}$ Faculty perspectives are also in line with these findings. In a study by Saunders, ${ }^{8}$ faculty agreed that IL is important for students, often using words like "critical" and "essential" when responding. One faculty member in Saunders' study said, "I can't think of anything you can do in the world today that you can do without this... [There is] no task that doesn't involve information. Every person in the world today at every level needs it." ${ }^{9}$ Another study, by Sophie Bury, also shows a "strong and enduring faculty belief in the value of solid student IL proficiencies,"10 and Lorna Dawes explores faculty's pedagogical and philosophical perceptions of teaching IL in her 2019 study. ${ }^{11}$ There is even an institutional recognition of the importance of IL in postsecondary education, as evidenced by the inclusion of an IL module for the National Survey of Student Engagement (NSSE) used by more than 200 institutions. $^{12}$

\section{IL Skill Needs}

A parallel focus of IL research in postsecondary institutions has been on what information literacy skills students need to be successful and whether they have them. The research suggests that students possess some IL knowledge even before they begin their postsecondary education. Kocevar-Weidinger, ${ }^{13}$ for instance, provides evidence that students understand searching as a multistep process involving different types of information and the corroboration of information across multiple sources. On the other hand, there remain many skills that students do not possess upon entering the postsecondary environment and that should be developed as part of library professionals' commitment to student success, especially given the correlation with other success measures noted above. Researchers have shown that most undergraduate students (and even some graduate students) will turn to Google before using more academic sources. ${ }^{14}$ Students also have trouble knowing where to start their searches, have been shown to have little understanding of advanced search options (like Boolean operators) that would help them narrow their searches to more relevant results, and some don't realize the limitations of nonacademic resources and/or know how to identify credible sources. ${ }^{15}$

Which IL skills students have and need has been examined in the literature at some length, ${ }^{16}$ but the specifics of how and when those skills are developed by discipline has received less attention. Only one study by Cope and Sanabria ${ }^{17}$ has tackled disciplinary differences in faculty perception of IL in the last 10 years; of the 20 interviews conducted, only a handful were in the sciences. The study concludes that disciplinary differences exist and provides some general guidance to librarians on what those differences might be. The science fields are the primary focus of this paper, and previous work has shown that the timelines and values underlying IL skills and instruction in science differ from those in other disciplines. ${ }^{18}$ The difficulty in reading, understanding, and appraising peer-reviewed literature in the sciences delays the development of other IL skills as compared to other fields. The Association of College \& Research Libraries 
(ACRL) recognizes the differing needs of science students in their science-targeted IL standards, Information Literacy Standards for Science and Engineering/Technology. ${ }^{19}$ The Standards are broken into a series of categories and subcategories, referred to as Standards and Performance Indicators respectively. In addition to the core IL skills common across disciplines, the Standards for Science and Engineering/Technology emphasize the importance of understanding how information is created in their fields, being able to recognize and make judgments on ethical, legal, and socioeconomic issues surrounding information they may be accessing, and knowing about and using the many kinds of information that are common to their fields.

The standards developed by ACRL, however, offer no indication about when each skill can or should be acquired during a science degree. Little information to this effect is available. Some studies, like one by Lantz and Dempsey, ${ }^{20}$ have reported on the skills possessed by specific science cohorts, and others have reported on faculty perspectives on science student IL skills. ${ }^{21}$ While these works do not refer to year of study, they underscore some of the differences between IL in the sciences and IL in other disciplines. The persistent refrain from this body of research is that science students often cannot interact with the peer-reviewed literature at a sophisticated level before a graduate level, with some faculty remarking that some of the statistical tools and methodologies used in the literature is beyond even their own understanding. ${ }^{22}$ In Perry's work, ${ }^{23}$ faculty interviews revealed that students often encountered and selected articles that were beyond their ability to understand, and "the question 'Would students be able to recognize and discard studies with methodological flaws?' received an almost unanimous 'no'."' ${ }^{24}$ Faculty also commented that a few advanced undergraduate students may have some ability to appraise methodology, but that it was generally not expected until the graduate level. Interestingly, however, the same study - and others ${ }^{25}$ - also found that science faculty place a high value on their students' ability to treat information critically and to evaluate sources.

\section{The Present Study}

Few librarians have science degrees, with one survey showing that, even among science, technology, engineering, and mathematics (STEM) librarians, only 30 percent have subjectspecific backgrounds. ${ }^{26}$ Similarly, a survey of 970 Canadian academic librarians conducted by the Canadian Association of Professional Academic Librarians (CAPAL) ${ }^{27}$ found that only 16 of the 346 master's degrees held by responding librarians were in the natural sciences. Academic training in the field helps librarians understand the needs of students at a granular level. Without knowing which, what, how, and when IL skills are needed, science librarians may struggle to know how best to support students in their disciplines. In fact, it can act as a barrier against library involvement in science IL instruction, as one of the primary reasons given by instructors for not collaborating with librarians is that their discipline-specific needs and expectations have not been met by librarians in the past. ${ }^{28}$

To address the knowledge gap about what IL skills are needed and when by undergraduate science students, this study used a mixed-methods approach. Faculty and instructors in biology, chemistry, and physics were surveyed in the first part of the study about 14 IL skills. For each of these skills, respondents indicated in which year of the program the skill was needed (if at all). The second part of the study involved 10 semistructured interviews to gain additional context and clarity. Results from both parts of the study were synthesized to help contextualize IL in the sciences and provide recommendations for librarians working in those fields. 


\section{Methods}

\section{Survey of Science Faculty}

Faculty and instructors teaching in four-year biology, chemistry, and physics degree programs were recruited using Canadian and American listservs. The listservs were chosen for their likelihood of serving actively teaching faculty and instructors in the fields they represent, for the number of candidates they were likely to capture, and for their representation across the three scientific fields under consideration. Local instructors were also consulted as field experts for specific listserv recommendations. The listservs used were ECOLOG-L of The Ecological Society of America, the Chemistry Education Division list of the Chemical Institute of Canada, the distribution lists of the Society for College Science Educators and the Canadian Association of Physicists (CAP), and Advlabs-L of the American Association of Physics Teachers. Other associations offering listservs were also approached as distributors for the survey, but they either declined participation or failed to respond to email requests. An introductory email describing the purpose and nature of the study, including a link to the survey, was sent to potential participants. As compensation for responding to the survey, each participant could enter a drawing to win one of two $\$ 100$ gift cards (CAD or equivalent). The project was approved by the University of New Brunswick Research Ethics Board.

The survey (see appendix A) was built in the LimeSurvey platform, took between 5 and 7 minutes to complete, and had 18 questions, the majority of which were multiple choice. The survey opened with two questions about the discipline and geographic area of the respondent. These questions were followed by a multiple-choice array with 14 information literacy skills and asked the respondent to "please indicate the point at which students in your degree program should have the following skills (particularly as they relate to the literature/information types used in your field)." Elements recognized in both ACRL's Information Literacy Standards for Science and Engineering and the literature on student IL needs, such as the ability to critically appraise information, generated the IL skills questions. Each skill had response options of "first year," "second year," "third year," "fourth year," "Graduate," "N/A," and "No answer." The survey closed with two additional questions, which addressed the major reference/discipline-specific resources and a final opportunity for instructors to comment on any other important information topics that might not have already been addressed. The survey was designed by the principal investigator (PI) and reviewed separately by the co-investigators (Co-Is); then it was assessed by two external researchers for bias, ambiguity, and overall clarity. It was also released in stages so that any issues discovered in the survey could be resolved with minimal impact on responses; no such issues were reported once it had been released, and it remained unchanged throughout the distribution phase. The survey remained open until no new responses had been received for at least one week. The majority of responses were received within the first three days of distribution on any given listserv.

Of the 174 surveys collected, a total of 120 were included in this study. Surveys that were not included were less than 50 percent complete or failed to report the discipline of the respondent. Of the 120 surveys included in the analysis, 45 of the respondents taught biology, 32 taught chemistry, and 43 taught physics. Regarding geographic context, 42 percent of respondents were teaching in Canada at the time of response, and 58 percent were teaching in the United States. 


\begin{tabular}{|c|c|c|c|c|}
\hline $\begin{array}{l}\text { TABLE } 1 \\
\text { The median responses to each of the } 14 \text { IL skill questions indic } \\
\text { a skill is required. Responses are shown both as a total across }\end{array}$ & $\begin{array}{l}\text { ing in } \\
\text { he scie }\end{array}$ & $\begin{array}{l}\text { hich yea } \\
\text { ices and }\end{array}$ & $\begin{array}{l}\text { f the } \\
\text { disci }\end{array}$ & \\
\hline Please indicate the point at which students in your degree program & $\mathrm{Me}$ & dian of Year & n Prograr & \\
\hline should have the following skills: & Biology & Chemistry & Physics & All \\
\hline $\begin{array}{l}\text { Recognize the purpose, audience, and value of different } \\
\text { information sources }\end{array}$ & 2 & 2 & 2 & 2 \\
\hline $\begin{array}{l}\text { Recognize that information may need to be constructed from raw } \\
\text { data or experiments }\end{array}$ & 2 & 2 & 2 & 2 \\
\hline $\begin{array}{l}\text { Recognize and use field-specific information sources (like manuals, } \\
\text { handbooks, and the like) }\end{array}$ & 2 & 2 & 2 & 2 \\
\hline Synthesize information to draw direct conclusions & 2 & 2 & 2 & 2 \\
\hline Read and understand most scientific articles in the field & 4 & 4 & $\begin{array}{l}\text { Grad } \\
\text { school }\end{array}$ & 4 \\
\hline $\begin{array}{l}\text { Assess the tools, methodologies, and/or analyses in a study to } \\
\text { determine their appropriateness }\end{array}$ & 4 & 4 & $\begin{array}{l}\text { Grad } \\
\text { school }\end{array}$ & 4 \\
\hline $\begin{array}{l}\text { Identify the correct searching tool for the type of information } \\
\text { needed (such as library catalogue or database) }\end{array}$ & 2 & 2 & 2 & 2 \\
\hline Construct a search that uses appropriate keywords and synonyms & 2 & 2 & 2 & 2 \\
\hline $\begin{array}{l}\text { Construct a search that uses advanced searching syntax (like } \\
\text { Boolean operators, proximity searching, truncation, and others) }\end{array}$ & 2 & 2 & 3 & 3 \\
\hline $\begin{array}{l}\text { Recognize that a search needs to be refined and adjust it } \\
\text { appropriately }\end{array}$ & 2 & 2 & 3 & 2 \\
\hline $\begin{array}{l}\text { Examine and compare information from various sources to evaluate } \\
\text { it for validity }\end{array}$ & 2 & 2 & 3 & 3 \\
\hline Analyze the structure and logic of supporting arguments & 2 & 3 & 3 & 3 \\
\hline $\begin{array}{l}\text { Recognize prejudice, deception, and/or manipulation in } \\
\text { information or its use }\end{array}$ & 3 & 3 & 3 & 3 \\
\hline $\begin{array}{l}\text { Extend initial synthesis of information at a higher level of } \\
\text { abstraction to construct a new hypothesis }\end{array}$ & 3 & 4 & 4 & 4 \\
\hline
\end{tabular}

\section{Survey Results}

The medians of the survey results, broken down by question and discipline, are shown in table 1. The median was chosen as the measure of central tendency for this survey because of the essentially nominal (and therefore discontinuous) nature of the data and because it is more resistant to outliers than the mean. Tables 2 and 3, indicating the means, standard deviations, and modes of the responses by question and discipline, are available in appendix B.

Respondents were also asked to list up to five reference sources they felt were critical to their disciplines and with which their students needed to be familiar. The most frequently mentioned resources by discipline were science journals and databases (biology and physics), and the CRC Handbook of Chemistry and Physics (chemistry). A table listing other frequently mentioned reference sources by discipline is available in appendix $C$.

Some of the survey results raised questions that required deeper exploration:

1. Why are none of the 14 skills queried in the survey considered essential in a student's 
first year of study (as captured in table 1), and what implications does this have on the types of IL instruction they receive and resources they access in their first year?

2. Why are students not expected to be able to read and understand research articles until late in their degrees and yet are expected to be able to perform advanced database searches and consider information critically before then? Table 1 indicates that faculty and instructors expect these skills to have developed by the fourth year or the graduate level.

3. Since students are unable to read and understand research articles until the fourth year, what resources should they be searching for and using for their degrees? This question was partially, but not sufficiently, answered by the reference sources suggested by survey respondents.

These questions emerging from the survey results informed the choice and development of the interview questions that comprised the second part of this study.

\section{Follow-Up Interviews}

In part 2 of the study, questions raised from the survey results were addressed through interviews with respondents. At the end of the survey in part 1, respondents were asked if they were willing to be contacted later for further information. A list of the 54 respondents who so indicated was compiled, and all were invited to participate in the interview phase of this project. Participants were recruited using email invitations and offered a \$20 (CAD or equivalent) gift card to thank them for their time. Ten respondents agreed to be interviewed (response rate: 18.5\%): 3 from biology, 3 from chemistry, and 4 from physics.

Interviews were conducted by the PI using the video conferencing platform preferred by the interviewee. Interviews were audiorecorded for transcription purposes and ranged between 10 and 20 minutes in length. A semistructured interview format was used, in which four questions were asked of all interviewees and allowed for additional clarifying questions. The questions were emailed to the interviewees prior to the interview, so the interviewees could consider their responses, and then the questions were repeated during the interview. These were the questions:

1. According to the results of our survey, science students are generally not expected to be able to read and understand most articles in their discipline until around the fourth year. Why do you think that is?

2. If students are not using articles effectively until later in their undergraduate degrees, what kinds of resources should they be relying on in the first and second years?

3. According to the results of our survey, students should be achieving the ability to read and understand articles and the ability to critically assess information at around the same time. How do you think these skills develop/co-develop?

4. According to the results of our survey, students should be developing database searching skills during their second and third years. What kinds of information should they be targeting/retrieving with these searches?

Upon completion, all interviews were divided among and transcribed by the PI and Co-Is and analyzed using a multistep process. First, the PI immersed herself in the data by reviewing the transcripts several times to ensure a full recollection of the content of the interviews. Next, the PI extracted distinct concepts and statements, in the form of participant quotes, from each interview transcript and collated those statements in one location. These statements were 
then reviewed again, and the PI assigned each a preliminary code that captured its meaning. Like-coded items were grouped together, and the preliminary codes were updated to reflect the broader theme within those groups. The Co-Is then were given the codes and reviewed the transcripts with those codes in mind. They made notes as they reviewed and consulted the coding done by the PI. Conflicts in coding were resolved collaboratively, and some adjustments to the naming of codes was made. The coding was complete when all authors agreed that the codes had been applied accurately, consistently, and completely to all the interview data. Six major themes emerged from this process and are discussed below.

\section{Themes from the Interviews}

Six themes emerged from the interviews: 1) research articles in the sciences are written for experts, not students; 2) there is value in having students read articles even if they aren't fully understood; 3) students are unable to critically appraise research in articles; 4) students are able to evaluate information sources for nonscientific content; 5) there are many information sources other than the peer-reviewed research that are appropriate for science students; and 6) instructors consider science students' searching skills to be underdeveloped. These themes and the responses that led to their development are described in detail below. Quotes from the interviews, which are provided theme by theme below, are associated with the interviewee using that interviewee's academic rank and discipline to preserve their anonymity while indicating disciplinary context.

Research articles in the sciences are written for experts, not students Interviewees agreed, almost unanimously, that primary research articles are not intellectually accessible to first- and second-year undergraduate students. Common reasons given included the highly technical language used in scientific writing, siloing among the sciences that makes it hard to understand research outside of a specific subdiscipline, and the amount of background knowledge needed to understand current research. "We silo out so early and so intensely that until you get to a graduate level [students are] not even going to understand all of the, most of, the material in [their] own field" (Instructor, chemistry). Another interviewee stated, "It's because in our field knowledge is very cumulative [...] the amount of knowledge you need to be able to read the literature is quite extensive." (Professor, physics) Underscoring this, four of the 10 interviewees said that even they couldn't read all the articles in their fields. An instructor in chemistry said, "I understand one type of physical chemistry article so I... I can understand spectroscopy articles, but I wouldn't be able to follow fully anything else, period. Sometimes even within other physical chemistry journals."

\section{There is value in having students read articles even if they aren't fully understood} Despite a general acknowledgment that first- and second-year undergraduate students can't be expected to read and understand most articles in their disciplines, four interviewees expressed a belief that there was still value in having them read articles. A senior instructor in chemistry explained, "I think that even before fourth year, students could get something out of an article." These interviewees highlighted skills like parsing important information and developing an understanding of an article's structure and layout. The same senior instructor in chemistry clarified, 'Going back to 'do they understand every piece of the article?', maybe not, but in [a previously mentioned] example they very much should be able to use that ar- 
ticle to say: 'oh, this showed that microwave degraded the vitamin C by $50 \%$."' Similarly, an assistant professor in biology talked about the importance of teaching students "how to take away, for a journal article, what you need to take away from it without getting lost in the minutiae" that they can't understand. In general, interviewees perceived methods sections as the most significant barriers to students, while abstracts, introductions, discussions and conclusions contain at least some information intellectually accessible to students.

\section{Students are unable to critically appraise research in articles}

Interviewees unanimously agreed that the ability to critique an article for its content is most often developed during graduate degrees. A few key exceptions were mentioned by four interviewees: particularly gifted fourth-year students, some students after completion of their thesis work, and students in a course where critiquing articles is a specific learning goal. Overall, though, interviewees agreed with this professor of physics, that "it's harder to be critical unless you're right in the middle of it, and those skills probably-in my opinion anyway-would develop more strongly in graduate school." (Professor, physics)

\section{Students are able to evaluate information sources for nonscientific content}

Five interviewees mentioned various ways students can assess research articles-and other information sources - that do not require a full understanding of the content. "Things like who is thinking up the research questions, who's funding the research, different kinds of equity issues" were highlighted by a senior instructor in chemistry, while an assistant professor in biology said the ability to question "'Is this a good source,' 'what are the biases,' 'who's the audience that's being written for,' should come before they develop the ability to read journal articles." Interviewees also talked about the importance of knowing what different types of information are available and the strengths and limitations of each.

There are many information sources other than the peer-reviewed research that are appropriate for science students

When asked about the types of resources most appropriate for first- and second-year undergraduate students, interviewees offered a wide variety of options. Following are several frequently mentioned resources:

- Reviews: Five of 10 interviewees mentioned reviews - peer-reviewed topic overviews because of their tendency to be easy to read and the lack of challenging methods sections.

- Textbooks: Five interviewees identified textbooks as good information sources, again because of readability.

- Easy journals: Three interviewees noted "easy journals" had primary research articles that were more intellectually accessible. An easy journal was defined by two interviewees as those with high-impact factors (such as Nature or Science) because they felt the writing standards tend to be higher in those journals, making their articles easier to read and understand. The remaining interviewee described easy journals as being science education journals, which are scientific in nature but are meant to be accessible to nonscientists.

- Blogs, online digests, forums, and the like: Three interviewees recommended platforms where students could interact with researchers or where they could read about scientific work without having to engage with the peer-reviewed literature. 
Other resources mentioned by only one or two respondents included popular science articles, audiovisual media and podcasts, educational resources, reference tools, sections of primary articles, safety sheets, science websites, news, and course notes.

An additional recurring suggestion in the context of resources (mentioned by five interviewees) was that lower-year undergraduate students could be well served by an instructorcurated list of resources. Such a curated list could have a range of resource types and might contain peer-reviewed research that the instructor deemed intellectually accessible to the students, or high-quality but non-peer-reviewed materials.

\section{Instructors consider science students' searching skills to be underdeveloped}

Seven of the interviewees mentioned some aspect of their students' literature searching abilities, and most of their comments concerned their students' lack of formal training. Interviewees indicated that their students seldom received literature searching instruction-either from a librarian or from their course instructors - and their use of searching tools like Boolean operators was thought more likely to be accidental than deliberate. Two interviewees suggested that advanced searching skills are not necessary for students since they are using Google or other databases where they can locate relevant results despite poor search skills. A professor of physics addressed both elements by observing that "students are unknowingly using Boolean searches already by going into Google ... and just typing as many words as they can think of."

\section{Discussion}

This study offers considerable insight into science faculty's expectations of their students' IL skills not previously captured in the literature. These insights are instructive for science librarians, especially those for whom the study of science is not in their own educational background. The combination of the facts gathered in the survey and corresponding themes gathered in the interviews yields particularly interesting insights into how faculty and science librarians might provide more timely and relevant IL instruction to undergraduates. The patterns that emerge from these pairings are the focus of this discussion.

Respondents in both the survey and interviews agree, almost unanimously, that science students should not be expected to fully understand peer-reviewed research in their fields until at least their fourth year and often not until the graduate level. Analysis of the interviews explained that this is due to the highly technical nature of the peer-reviewed research, the intense siloing within scientific subdisciplines, and a need for extensive background knowledge to understand it. Despite these challenges, however, several interviewees did suggest that students can benefit from reading research articles because they should be able to parse out some of the important information and also develop a better understanding of the shape and nature of peer-reviewed literature in their fields.

Faculty and instructor responses also suggested that the ability to read and understand the literature develops at around the same time as their ability to treat information critically. What was unclear at the time of the survey was how that co-development occurred. From the interviews, the authors found that, on the one hand, students are not able to critically assess peer-reviewed research for its content-the methodologies being employed, for example, or the appropriateness of a specific statistical analysis - until graduate school. On the other hand, not all critical appraisal of information sources requires a deep understanding of the content. Judgments about the presence of bias, funding and equity issues, authority of author 
or publisher, and who the target audience is can be made early in a science degree, as they have little to do with complicated and intellectually inaccessible article content.

The study also shows the belief by faculty and instructors that science students need to be able to build advanced searches in databases (using Boolean operators, proximity terms, and so on) in their second and third years, though there were concerns about their students' ability to do so, with several interviewees expressing disappointment at students' poor skills and the lack of training students receive.

Finally, given the acknowledged complexity and intellectual inaccessibility of the peerreviewed research in the sciences in both phases of the study, there was a critical need to know what kinds of resources would best serve science students early in their undergraduate careers. Part of the answer to this was provided in the survey in the form of a list of reference sources that were important for students in each of the natural sciences, but this list failed to fully capture the breadth and diversity of information types in the sciences as it focused only on published reference sources. Faculty and instructors expanded on this, identifying other types of information sources that their students should be using early in their degrees without specific titles or sources. Their responses included reviews, textbooks, easy journals, blogs, online digests, forums, popular science writings, and more.

In deciding if or how to implement changes based on the results of this study, it is important to consider the limitations in the design. In particular, this study faced two challenges in data collection: sampling response rate and the number of questions that could reasonably be asked of the respondents. In the matter of response rate, the use of listservs was essential for our recruitment methodology, as it allowed us to sample a large number of faculty and instructors across the relevant disciplines while still managing to target our survey effectively to that population. However, listservs also present unknowns, most notably the number of people subscribed. Thus, the authors were unable to determine how widely the survey was distributed, making it impossible to calculate a response rate. The authors speculate that the low response rate to the invitation to be interviewed (\# of survey respondents vs interviews) may be an indication of an overall low response rate to the survey itself. However, this concern is diminished by the high level of agreement across participants in both parts of the study. It is likely that a higher response rate would simply reinforce what was found in this study without changing the results or conclusions.

In the matter of the number of questions that could reasonably be asked, the survey was designed to collect as much impactful information as possible while placing as little burden on the respondents as possible to help maximize our response rate. There are additional questions that could have been asked, such as whether tenured faculty and term-instructors differ in their perspectives on undergraduate IL needs. The authors chose to exclude these questions in favor of greater emphasis and specificity on the topic of IL needs in the interest of focusing on concrete teaching and learning objectives to facilitate science librarians working with students. Future research is needed to address these other aspects of IL in the sciences.

\section{Recommendations for Practice}

The findings from both the survey and interviews align with previous research done on information use and literacy in the sciences, such as that done by Perry ${ }^{29}$ and Lantz and Dempsey. ${ }^{30}$ It builds on their work by drawing attention to specific aspects of information in those fields that may impact student development of those skills. Based on our findings, and acknowledg- 
ing the widely accepted value of and need for discipline-specific IL instruction, the authors offer three recommendations to librarians teaching science students:

1. Science librarians should continue to focus on teaching database search skills, but they should consider the scientific reading level of their students and teach skills that help students find more topical and intellectually accessible materials (like reviews) in academic databases. Such searching instruction could also include teaching students to parse the retrieved research articles for the information suitable to their level.

2. In addition to database searching skills, science librarians should focus on directing first- and second-year undergraduate students to non-peer-reviewed materials that are intellectually accessible to them. They should point students toward formats they can fully understand like popular science articles, forums, and the like.

3. When discussing appraisal of the literature, science librarians should focus on teaching upper-year undergraduates evaluation of environmental and contextual elements of the research, without requiring them to critique the research methodologies and results themselves.

Effective information literacy instruction has a significant impact on student success. This is just as true in undergraduate science programs as in any other field, but little has been known about whether science librarians are equipping students with the right skills at the right time. This paper offers direction for librarians teaching in the sciences to facilitate effective, evidence-based practice. 


\section{APPENDIX A}

(formatted from digital original)

Requirements

- 4-year degree program

- Biology, Chemistry, or Physics

- Faculty or instructor

What discipline do you teach in? Chemistry Biology Physics

What province/state is your university/college in?

\section{TABLE 1}

Please indicate the point at which students in your degree program should have the following skills (particularly as they relate to the literature/information types used in your field):

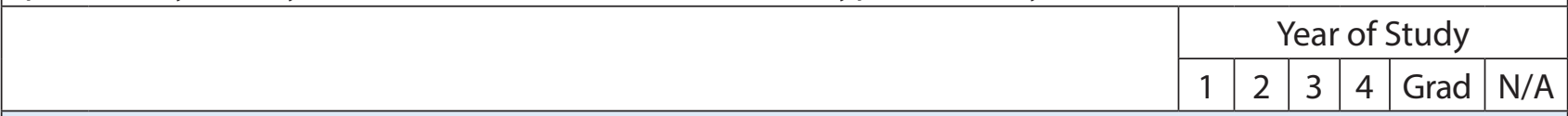

\section{General information literacy}

Please indicate the point at which students in your degree program should have the following skills:

1 Recognize the purpose, audience, and value of different information sources

$2 \quad$ Recognize that information may need to be constructed from raw data or experiments

$3 \quad$ Recognize and use field-specific information sources (like manuals, handbooks, and other sources)

$4 \quad$ Synthesize information to draw direct conclusions

With specific emphasis on published journal articles

Please indicate the point at which students in your degree program should have the following skills:

$5 \quad$ Read and understand most scientific articles in the field

6 Assess the tools, methodologies, and/or analyses in a study to determine their appropriateness

\section{Searching for information}

Please indicate the point at which students in your degree program should have the following skills:

$7 \quad$ Identify the correct searching tool for the type of information needed (such as library catalogue, database, or other searching tool)

8 Construct a search that uses appropriate keywords and synonyms

9 Construct a search that uses advanced searching syntax (like Boolean operators, proximity searching, truncation, and other searching tools)

10 Recognize that a search needs to be refined and adjust it appropriately

Thinking critically about information

Please indicate the point at which students in your degree program should have the following skills:

11 Examine and compare information from various sources to evaluate it for validity

12 Analyze the structure and logic of supporting arguments

13 Recognize prejudice, deception, and/or manipulation in information or its use

14 Extend initial synthesis of information at a higher level of abstraction to construct a new hypothesis

\begin{tabular}{|l|l|l|l|l|l}
\hline & & & & & \\
\hline & & & & & \\
\hline & & & & & \\
\hline & & & & & \\
\hline
\end{tabular}


What reference/field-specific resources are most important for students in your discipline to know? (such as CRC handbook, conversion tables, major handbooks and manuals, and the like)

1.

2.

3.

4.

5.

Are there any other important topics related to information/literature that your students need to know about, and when in their degrees would they need to know it?

Are you willing to be contacted in the future to discuss this further? Yes No Are you interested in entering to win a $\$ 100$ gift card? Yes No

Would you like to receive a summary of the study results? Yes No

Contact information: (email address) 


\section{APPENDIX B}

\section{TABLE 2}

The mean responses with standard deviations to each of the 14 IL skill questions, in which the values 1-4 indicate the year of the undergraduate program in which a skill is required, and 5 indicates that the skill is not expected until graduate school. Responses are shown both as a total across the sciences and by discipline.

\begin{tabular}{|c|c|c|c|c|c|c|c|c|}
\hline \multirow{2}{*}{$\begin{array}{l}\text { Please indicate the point at which students } \\
\text { in your degree program should have the } \\
\text { following skills: }\end{array}$} & \multicolumn{2}{|c|}{ Biology } & \multicolumn{2}{|c|}{ Chemistry } & \multicolumn{2}{|c|}{ Physics } & \multicolumn{2}{|c|}{ All } \\
\hline & $M$ & SD & $M$ & SD & $M$ & $\mathrm{SD}$ & $M$ & SD \\
\hline $\begin{array}{l}\text { Recognize the purpose, audience, and value of } \\
\text { different information sources }\end{array}$ & 1.89 & 1.01 & 1.69 & 0.86 & 2.07 & 1.03 & 1.90 & 0.98 \\
\hline $\begin{array}{l}\text { Recognize that information may need to be } \\
\text { constructed from raw data or experiments }\end{array}$ & 1.67 & 0.64 & 1.81 & 1.00 & 1.86 & 0.86 & 1.78 & 0.82 \\
\hline $\begin{array}{l}\text { Recognize and use field-specific information } \\
\text { sources (like manuals, handbooks, and other } \\
\text { sources) }\end{array}$ & 2.09 & 1.12 & 1.81 & 0.97 & 2.36 & 0.88 & 2.11 & 1.01 \\
\hline $\begin{array}{l}\text { Synthesize information to draw direct } \\
\text { conclusions }\end{array}$ & 2.42 & 1.18 & 2.28 & 1.08 & 2.56 & 0.93 & 2.43 & 1.07 \\
\hline $\begin{array}{l}\text { Read and understand most scientific articles in } \\
\text { the field }\end{array}$ & 3.56 & 0.99 & 3.72 & 1.14 & 4.45 & 0.74 & 3.92 & 1.03 \\
\hline $\begin{array}{l}\text { Assess the tools, methodologies, and/ } \\
\text { or analyses in a study to determine their } \\
\text { appropriateness }\end{array}$ & 3.89 & 1.05 & 3.56 & 1.11 & 4.30 & 0.86 & 3.95 & 1.04 \\
\hline $\begin{array}{l}\text { Identify the correct searching tool for the } \\
\text { type of information needed (such as library } \\
\text { catalogue, database, or other searching tool) }\end{array}$ & 2.00 & 1.07 & 2.09 & 1.03 & 2.58 & 1.01 & 2.23 & 1.06 \\
\hline $\begin{array}{l}\text { Construct a search that uses appropriate } \\
\text { keywords and synonyms }\end{array}$ & 1.89 & 0.96 & 2.06 & 0.98 & 2.26 & 1.09 & 2.07 & 1.02 \\
\hline $\begin{array}{l}\text { Construct a search that uses advanced } \\
\text { searching syntax (like Boolean operators, } \\
\text { proximity searching, truncation, and other } \\
\text { searching tools) }\end{array}$ & 2.56 & 1.29 & 2.48 & 1.29 & 2.89 & 1.03 & 2.65 & 1.21 \\
\hline $\begin{array}{l}\text { Recognize that a search needs to be refined } \\
\text { and adjust it appropriately }\end{array}$ & 2.53 & 1.25 & 2.22 & 1.01 & 2.71 & 1.02 & 2.51 & 1.12 \\
\hline $\begin{array}{l}\text { Examine and compare information from } \\
\text { various sources to evaluate it for validity }\end{array}$ & 2.60 & 1.16 & 2.56 & 1.19 & 2.93 & 1.12 & 2.71 & 1.16 \\
\hline $\begin{array}{l}\text { Analyze the structure and logic of supporting } \\
\text { arguments }\end{array}$ & 2.60 & 1.19 & 2.78 & 1.24 & 3.02 & 1.01 & 2.80 & 1.15 \\
\hline $\begin{array}{l}\text { Recognize prejudice, deception, and/or } \\
\text { manipulation in information or its use }\end{array}$ & 2.89 & 1.27 & 3.19 & 1.47 & 3.07 & 1.23 & 3.03 & 1.31 \\
\hline $\begin{array}{l}\text { Extend initial synthesis of information at a } \\
\text { higher level of abstraction to construct a new } \\
\text { hypothesis }\end{array}$ & 3.56 & 1.06 & 3.56 & 1.24 & 3.95 & 0.87 & 3.70 & 1.06 \\
\hline
\end{tabular}




\section{TABLE 3}

The mode of the responses to each of the $14 \mathrm{IL}$ skill questions, in which the values 1-4 indicate the year of the undergraduate program in which a skill is required, and 5 indicates that the skill is not expected until graduate school. Responses are shown both as a total across the sciences, and by discipline.

\begin{tabular}{|c|c|c|c|c|}
\hline \multirow{2}{*}{$\begin{array}{l}\text { Please indicate the point at which students in your degree } \\
\text { program should have the following skills: }\end{array}$} & \multicolumn{4}{|c|}{ Mode } \\
\hline & Biology & Chemistry & Physics & All \\
\hline $\begin{array}{l}\text { Recognize the purpose, audience, and value of different } \\
\text { information sources }\end{array}$ & 1 & 1 & 1 & 1 \\
\hline $\begin{array}{l}\text { Recognize that information may need to be constructed from raw } \\
\text { data or experiments }\end{array}$ & 2 & 1 & 1 & 1 \\
\hline $\begin{array}{l}\text { Recognize and use field-specific information sources (like manuals, } \\
\text { handbooks, and other sources) }\end{array}$ & 1 & 1 & 2 & 2 \\
\hline Synthesize information to draw direct conclusions & 1 & 2 & 2 & 2 \\
\hline Read and understand most scientific articles in the field & 3 & 5 & 5 & 5 \\
\hline $\begin{array}{l}\text { Assess the tools, methodologies, and/or analyses in a study to } \\
\text { determine their appropriateness }\end{array}$ & 5 & 4 & 5 & 5 \\
\hline $\begin{array}{l}\text { Identify the correct searching tool for the type of information } \\
\text { needed (such as library catalogue, database, or other searching } \\
\text { tool) }\end{array}$ & 1 & 1 & 2 & 2 \\
\hline Construct a search that uses appropriate keywords and synonyms & 1 & 1 & 2 & 2 \\
\hline $\begin{array}{l}\text { Construct a search that uses advanced searching syntax (like } \\
\text { Boolean operators, proximity searching, truncation, and other } \\
\text { searching tools) }\end{array}$ & 2 & 3 & 3 & 3 \\
\hline $\begin{array}{l}\text { Recognize that a search needs to be refined and adjust it } \\
\text { appropriately }\end{array}$ & 2 & 3 & 3 & 2 \\
\hline $\begin{array}{l}\text { Examine and compare information from various sources to } \\
\text { evaluate it for validity }\end{array}$ & 2 & 2 & 2 & 2 \\
\hline Analyze the structure and logic of supporting arguments & 2 & 3 & 3 & 3 \\
\hline $\begin{array}{l}\text { Recognize prejudice, deception, and/or manipulation in } \\
\text { information or its use }\end{array}$ & 3 & 5 & 4 & 2 \\
\hline $\begin{array}{l}\text { Extend initial synthesis of information at a higher level of } \\
\text { abstraction to construct a new hypothesis }\end{array}$ & 3 & 4 & 4 & 4 \\
\hline
\end{tabular}




\section{APPENDIX C}

Reference sources mentioned by two or more survey respondents:

TABLE 4

Reference sources listed by at least two respondents as being critical to their disciplines. Each respondent had the option of listing up to five such resources. Each reference source listed is followed by a bracketed number indicating how many times it was provided in answer to this question. Some of the resources/resource types in this table might arguably not be considered reference sources, but the authors did not deem such judgments sufficient to exclude them from the table.

\begin{tabular}{l}
\hline Biology \\
\hline Bergey's Manual of Systematic Bacteriology (2) \\
Textbooks (2) \\
Field guides/manuals (4) \\
Google Scholar (2) \\
Science journals/databases (6) \\
Taxonomic keys (2) \\
\hline Chemistry \\
CRC Handbook (17) \\
Chemistry websites (2) \\
Internet (2) \\
Merck Index (2) \\
NIST Chemistry WebBook (2) \\
Perry's Chemical Engineers Handbook (2) \\
SciFinder (6) \\
Spectral databases (2) \\
Science journals/databases (10) \\
Textbooks (5) \\
\hline Physics \\
\hline ArXiv (2) \\
CRC Handbook (9) \\
Instrument manuals (2) \\
Integral tables (4) \\
NIST (2) \\
Particle Data Group Handbook (6) \\
Science journals/databases (13)
\end{tabular}

\section{Notes}

1. D. Ellis, "Modeling the Information-Seeking Patterns of Academic Researchers: A Grounded Theory Approach," Library Quarterly 63, no. 4 (1993): 469-86, https://doi.org/10.1086/602622.

2. Melissa Bowles-Terry, "Library Instruction and Academic Success: A Mixed-Methods Assessment of a Library Instruction Program," Evidence Based Library and Information Practice 7, no. 1 (2012): 82-95, https://doi. org/10.18438/B8PS4D; Joni Blake et al., “The Impact of Information Literacy Instruction on Student Success: A Multi-Institutional Investigation and Analysis," Central University Libraries Research 13 (2017): 1-27; Jason Vance et al., "Measuring the Impact of Library Instruction on Freshmen Success and Persistence: A Quantitative Analysis," Communications in Information Literacy 6, no. 1 (2012): 49-58, https://doi.org/10.15760/comminfolit.2012.6.1.117.

3. Melissa Gross and Don Latham, "Undergraduate Perceptions of Information Literacy: Defining, Attaining, and Self-Assessing Skills," College E Research Libraries 70, no. 4 (July 2009): 336-50; Melissa Gross and Don 
Latham, "Experiences with and Perceptions of Information: A Phenomenographic Study of First-Year College Students," Library Quarterly 81, no. 2 (April 2011): 161-86; Melissa Gross and Don Latham, "What's Skill Got to Do with It? Information Literacy Skills and Self-Views of Ability among First-Year College Students," Journal of the American Society for Information Science \& Technology 63, no. 3 (March 2012): 574-83; E. Kocevar-Weidinger et al., "On Their Own Terms: First-Year Student Interviews about Everyday Life Research Can Help Librarians Flip the Deficit Script," Reference Services Review 47, no. 2 (2019): 169-92, https://doi.org/10.1108/RSR-02-2019-0007.

4. Bowles-Terry, "Library Instruction and Academic Success."

5. Vance et al., "Measuring the Impact of Library Instruction on Freshmen Success and Persistence."

6. Blake et al., "The Impact of Information Literacy Instruction on Student Success."

7. Tom Rosman, Anne-Kathrin Mayer, and Günter Krampen, "A Longitudinal Study on Information-Seeking Knowledge in Psychology Undergraduates: Exploring the Role of Information Literacy Instruction and Working Memory Capacity," Computers \& Education 96 (2016): 94-108, https://doi.org/10.1016/j.compedu.2016.02.011; Francesca Marineo and Qingmin Shi, "Supporting Student Success in the First-Year Experience: Library Instruction in the Learning Management System," Journal of Library \& Information Services in Distance Learning 13, no. 1/2 (2019): 40-55, https://doi.org/10.1080/1533290X.2018.1499235.

8. L. Saunders, "Faculty Perspectives on Information Literacy as a Student Learning Outcome," Journal of Academic Librarianship 38, no. 4 (2012): 226-36, https://doi.org/10.1016/j.acalib.2012.06.001.

9. Saunders, "Faculty Perspectives on Information Literacy as a Student Learning Outcome."

10. Sophie Bury, "Learning from Faculty Voices on Information Literacy: Opportunities and Challenges for Undergraduate Information Literacy Education," Reference Services Review 44, no. 3 (January 1, 2016): 237-52, https://doi.org/10.1108/RSR-11-2015-0047.

11. Lorna Dawes, "Faculty Perceptions of Teaching Information Literacy to First-Year Students: A Phenomenographic Study," Journal of Librarianship and Information Science 51, no. 2 (2019): 545-60, https://doi. org/10.1177/0961000617726129.

12. K. Fosnacht, “Information Literacy's Influence on Undergraduates' Learning and Development: Results from a Large Multi-Institutional Study," College \& Research Libraries 81, no. 2 (2017), https://scholarworks.iu.edu/ dspace/handle/2022/24086.

13. Kocevar-Weidinger et al., "On Their Own Terms: First-Year Student Interviews about Everyday Life Research Can Help Librarians Flip the Deficit Script."

14. Alison J. Head, "Beyond Google: How Do Students Conduct Academic Research?" First Monday 12, no. 8 (August 6, 2007), https://doi.org/10.5210/fm.v12i8.1998.

15. Jillian R. Griffiths and Peter Brophy, "Student Searching Behavior and the Web: Use of Academic Resources and Google," Library Trends 53, no. 4 (Spring 2005): 539-54; Kirsty Williamson et al., "Research Students in the Electronic Age: Impacts of Changing Information Behavior on Information Literacy Needs," Communications in Information Literacy 1, no. 2 (February 11, 2008): 47-63, https://doi.org/10.15760/comminfolit.2008.1.2.9.

16. Boglarka S. Huddleston et al., "Faculty Perspectives on Undergraduate Research Skills: Nine Core Skills for Research Success," Reference \& User Services Quarterly 59, no. 2 (2019): 118-30.

17. Jonathan Cope and Jesus E. Sanabria, "Do We Speak the Same Language? A Study of Faculty Perceptions of Information Literacy," portal: Libraries and the Academy 14, no. 4 (October 2014): 475-501.

18. Ellis, "Modeling the Information-Seeking Patterns of Academic Researchers"; G.J. Leckie and A. Fullerton, "Information Literacy in Science and Engineering Undergraduate Education: Faculty Attitudes and Pedagogical Practices," College and Research Libraries 60, no. 1 (1999): 9-29, https://doi.org/10.5860/crl.60.1.9; H.B. Perry, "Information Literacy in the Sciences: Faculty Perception of Undergraduate Student Skill," College and Research Libraries 78, no. 7 (2017): 964-77, https://doi.org/10.5860/crl.78.964; Saunders, "Faculty Perspectives on Information Literacy as a Student Learning Outcome."

19. American Library Association, "Information Literacy Standards for Science and Engineering/Technology," Text, Association of College \& Research Libraries (ACRL), July 24, 2006, http://www.ala.org/acrl/standards/ infolitscitech.

20. C. Lantz and P.R. Dempsey, "Information Literacy Strategies Used by Second-and Third-Year Biology Students," Issues in Science and Technology Librarianship 2019, no. 92 (2019), https://doi.org/10.29173/istl13.

21. Perry, "Information Literacy in the Sciences"; Saunders, "Faculty Perspectives on Information Literacy as a Student Learning Outcome."

22. Perry, "Information Literacy in the Sciences."

23. Perry, "Information Literacy in the Sciences."

24. Perry, "Information Literacy in the Sciences."

25. Leckie and Fullerton, "Information Literacy in Science and Engineering Undergraduate Education."

26. Marc Songini, "Librarians Often Come up Short in STEM Degrees, Says Survey," JoVE (August 10, 
2018), https://www.jove.com/blog/librarian-blog/librarians-career-advancement/stem-librarians-face-gap-withaudiences-survey-indicates/.

27. Canadian Association of Professional Librarians, "2018 Census of Canadian Academic Librarians: User Guide and Results Summary," CAPAL/ACBAP 2018 Census of Canadian Academic Librarians (2018), https:// capalibrarians.org/wp/wp-content/uploads/2019/03/2018_Census_March_24_2019.pdf.

28. Saunders, "Faculty Perspectives on Information Literacy as a Student Learning Outcome."

29. Perry, "Information Literacy in the Sciences."

30. Lantz and Dempsey, "Information Literacy Strategies Used by Second-and Third-Year Biology Students." 